\title{
Encephalopathies with intracranial calcification in children: clinical and genetic characterization
}

\author{
Davide Tonduti ${ }^{1,2^{*}}$ D, Celeste Panteghini ${ }^{3}$, Anna Pichiecchio ${ }^{4}$, Alice Decio ${ }^{5,6}$, Miryam Carecchio ${ }^{1,3,7}$, Chiara Reale ${ }^{3}$, \\ Isabella Moroni ${ }^{1}$, Nardo Nardocci ${ }^{1}$, Jaume Campistol ${ }^{8}$, Angela Garcia-Cazorla ${ }^{8}$, Belen Perez Duenas ${ }^{8}$, Cerebral \\ Calcification International Study Group, Luisa Chiapparini ${ }^{9}$, Barbara Garavaglia ${ }^{3}$ and Simona Orcesi ${ }^{5}$
}

\begin{abstract}
Background: We present a group of patients affected by a paediatric onset genetic encephalopathy with cerebral calcification of unknown aetiology studied with Next Generation Sequencing (NGS) genetic analyses.

Methods: We collected all clinical and radiological data. DNA samples were tested by means of a customized gene panel including fifty-nine genes associated with known genetic diseases with cerebral calcification.

Results: We collected a series of fifty patients. All patients displayed complex and heterogeneous phenotypes mostly including developmental delay and pyramidal signs and less frequently movement disorder and epilepsy. Signs of cerebellar and peripheral nervous system involvement were occasionally present. The most frequent MRI abnormality, beside calcification, was the presence of white matter alterations; calcification was localized in basal ganglia and cerebral white matter in the majority of cases. Sixteen out of fifty patients tested positive for mutations in one of the fifty-nine genes analyzed. In fourteen cases the analyses led to a definite genetic diagnosis while results were controversial in the remaining two.
\end{abstract}

Conclusions: Genetic encephalopathies with cerebral calcification are usually associated to complex phenotypes. In our series, a molecular diagnosis was achieved in $32 \%$ of cases, suggesting that the molecular bases of a large number of disorders are still to be elucidated. Our results confirm that cerebral calcification is a good criterion to collect homogeneous groups of patients to be studied by exome or whole genome sequencing; only a very close collaboration between clinicians, neuroradiologists and geneticists can provide better results from these new generation molecular techniques.

Keywords: Cerebral calcification, Leukodystrophy, Aicardi-Goutières syndrome, Next generation sequencing

\section{Background}

Encephalopathies with intracranial calcification constitute a group of very disabling neurological disorders. The clinical presentation is highly heterogeneous, ranging from congenital static conditions such as Adams Oliver Syndrome (AOS) [1], biphasic disorders such as Aicardi-Goutières Syndrome (AGS) [2], to severe progressive diseases like Krabbe Disease (KD) [3]. All these conditions have in common the presence

\footnotetext{
* Correspondence: davidetondu@hotmail.com

${ }^{1}$ Child Neurology Unit, IRCCS Foundation C. Besta Neurological Institute, Milan, Italy

${ }^{2}$ Child Neurology Unit, V. Buzzi Children's Hospital, Milan, Italy

Full list of author information is available at the end of the article
}

of cerebral calcification on Computed Tomography (CT). Many hypotheses to explain calcium deposition in the brain have been formulated, including inflammation [4], microangiopathy [5], dystrophic process [6], abnormal metabolism of calcium [7].The identification of the molecular bases of different disorders allowed to partially clarify the pathophysiological mechanism leading to cerebral calcification in some conditions such as in disorders related to mutations in genes encoding endothelial tight junction proteins (e.g. $O C L N$ and JAM3) [8, 9], vascular basement membrane components (COL4A1 and COL4A2) [10-12], proteins involved in phosphate transport and calcium homeostasis (SLC20A2, one of the genes associated to Primary Familial

(c) The Author(s). 2018 Open Access This article is distributed under the terms of the Creative Commons Attribution 4.0 International License (http://creativecommons.org/licenses/by/4.0/), which permits unrestricted use, distribution, and 
Brain Calcification (PFBC) formerly known as Fahr's Disease) [13]. In this study, we focused on a group of patients affected by a paediatric onset genetic encephalopathy with cerebral calcification of unknown aetiology.

\section{Methods}

\section{Patients selection}

We enrolled patients referred for diagnostic work-up from 2007 to 2016 to Besta Neurological Institute (Milan, Italy), Mondino Neurological Institute (Pavia, Italy) and Sant Joan de Deu Hospital (Barcelona, Spain), who presented with a childhood onset encephalopathy with cerebral calcification.

Inclusion criteria were as follows: 1) Onset before 18 years of age; 2) Cerebral Calcification documented on CT brain scan; 3) At least one performed brain MRI scan; 4) Unknown molecular diagnosis. Acquired conditions causing cerebral calcification (i.e. congenital infections, tumors) were ruled out in all patients.

\section{Clinical and radiological data collection}

Clinical data revision focused particularly on age and signs/symptoms at onset and clinical picture at the age at genetic analysis.

Neuroradiological images were reviewed collegially by the authors (LC; AP; DT). Evaluation of MRIs included the presence and localization of cerebral calcification as well as additional cerebral alterations. Based on the type of MRI signal, we categorized white matter involvement into "demyelination", "hypomyelination" and "delayed myelination" according to the international accepted classification [14]. We used the term "uncertain" when available data were not sufficient to discriminate between hypomyelination and delayed myelination. Cerebral calcification localization was categorized as follows: cerebral cortex, white matter, basal ganglia (including all deep supratentorial grey nuclei), cerebellum, brainstem, medulla oblongata.

\section{Genetic analysis}

Patients were analyzed by Next Generation Sequencing (NGS) technique using a customized gene panel (Nextera Rapid Capture Custom Enrichment) containing known genes most frequently associated with diseases with cerebral calcification with childhood and adult onset (Table 1). The panel was designed with Illumina Design Studio tool. The region of interest was the gene CDS (Coding sequence) with $+/-20$ bp intronic flanking region for including splicing mutations. This panel was used for library preparation; then samples were analyzed by a Miseq system (Illumina), with 50X effective mean depth. The generated reads were aligned to human genome assembly hg19 and the identified variants were annotated (Variant-Studio2.2, Illumina) and filtered,
Table 1 Genes included in our customized gene panel (Nextera Rapid Capture Custom Enrichment)

\begin{tabular}{|c|c|}
\hline $\begin{array}{l}\text { Primary Familial Basal Ganglia } \\
\text { Calcification (PFBC) }\end{array}$ & Nasu Hakola Disease \\
\hline SLC20A2 & TYROBP \\
\hline PDGFB & TREM2 \\
\hline PDGFRB & Coats Plus Disease \\
\hline$X P R 1$ & CTC1 \\
\hline $\begin{array}{l}\text { Aicardi-Goutieres } \\
\text { Syndrome + RNASET2 }\end{array}$ & $\begin{array}{l}\text { Inborn error of folates } \\
\text { metabolism }\end{array}$ \\
\hline TREX1 (AGS1) & FOLRI \\
\hline RNASEH2B (AGS2) & SLC46A1 \\
\hline RNASEH2C (AGS3) & MTHFR \\
\hline RNASEH2A (AGS4) & DHFR \\
\hline SAMHD1 (AGS5) & MTFD1 \\
\hline ADAR1 (AGS6) & Occludin \\
\hline IFIH1 (AGS7) & OCLN \\
\hline RNASET2 & Collagen IV related disorders \\
\hline \multirow{2}{*}{$\begin{array}{l}\text { Cockayne syndrome and } \\
\text { other DNA repair disorders }\end{array}$} & COL4A1 \\
\hline & COLAA2 \\
\hline DDB2 & $\begin{array}{l}\text { Hemorrhagic destruction of the } \\
\text { brain subependymal calcification } \\
\text { and cataracts }\end{array}$ \\
\hline ERCC1 & JAM3 \\
\hline ERCC2 & Spondyloenchondrodysplasia \\
\hline ERCC3 & ACP5 \\
\hline ERCC4 & Carbonic Anhydrase Deficiency \\
\hline ERCC5 & CA2 \\
\hline ERCC6 & Congenital Dyskeratosis \\
\hline ERCC8 & DKC1 \\
\hline GTF2H5 & TERC \\
\hline MPLKIP & TERT \\
\hline POLH & TINF2 \\
\hline$X P A$ & NHP2 \\
\hline$X P C$ & NOP10 \\
\hline Adams Oliver syndrome & WRAP53 \\
\hline DOCK6 & RTEL1 \\
\hline Friede Syndrome & Other calcification genes \\
\hline AP1S2 & CoAsy \\
\hline Keutel Syndrome & PANK2 \\
\hline MGP & QDPR \\
\hline Nakajo Nishimura syndrome & CYP2U1 \\
\hline PSMB8 & GALC \\
\hline Raine Syndrome & $C 1 q B$ \\
\hline FAM20C & ISG15 \\
\hline
\end{tabular}

Group of genes are captured in bold 
focusing on rare variants (minimum allele frequency $<1 \%$ in 1000 Genome Project [www.1000genomes.org] and ExAc [http://exac.broadinstitute.org] and Exome Sequencing Project, [http://evs.gs.washington.edu/EVS/], databases) and causing changes potentially damaging for the protein function (Polyphen2, SIFT and Mutation Taster). Conservation of alterated aminoacid was investigated with BLAST [https://blast.ncbi.nlm.nih.gov/ Blast.cgi]. Sanger sequencing was performed to confirm the mutation in each patient and the segregation within the family, where possible.

\section{Results}

Fifty subjects (twenty-one females and twenty-nine males) were included in the study. Clinical and radiological data are summarized in Fig. 1. Genetic results are presented in Table 2 . The most relevant results are described hereafter.

\section{Clinical data}

The mean age of onset was 17 months (range: prenatal to 13 years; $25^{\circ}$ percentile neonatal, $75^{\circ}$ percentile 11 years). Patients presented the following signs or symptoms at onset developmental delay (nineteen subjects; 38\%), seizures (nine; 18\%), neurodevelopmental regression (seven; 14\%), movement disorder (four; 8\%), neonatal acute encephalopathy (four; $8 \%$ ), deafness (one; 2\%) other (four; $8 \%$ ); the latter included psychiatric disorders, visual impairment, language delay. In two patients (4\%) signs of cerebral abnormalities were already present before birth on fetal ultrasound.

The mean time between clinical onset and molecular analysis (NGS) was 10 years and 7 months (range: 10 months to 33 years; $25^{\circ}$ percentile 5 years, $75^{\circ}$ percentile 15 years). At the time of analysis, the clinical picture was characterized by the presence of cognitive impairment in forty-four out of fifty subjects (88\%), pyramidal signs in

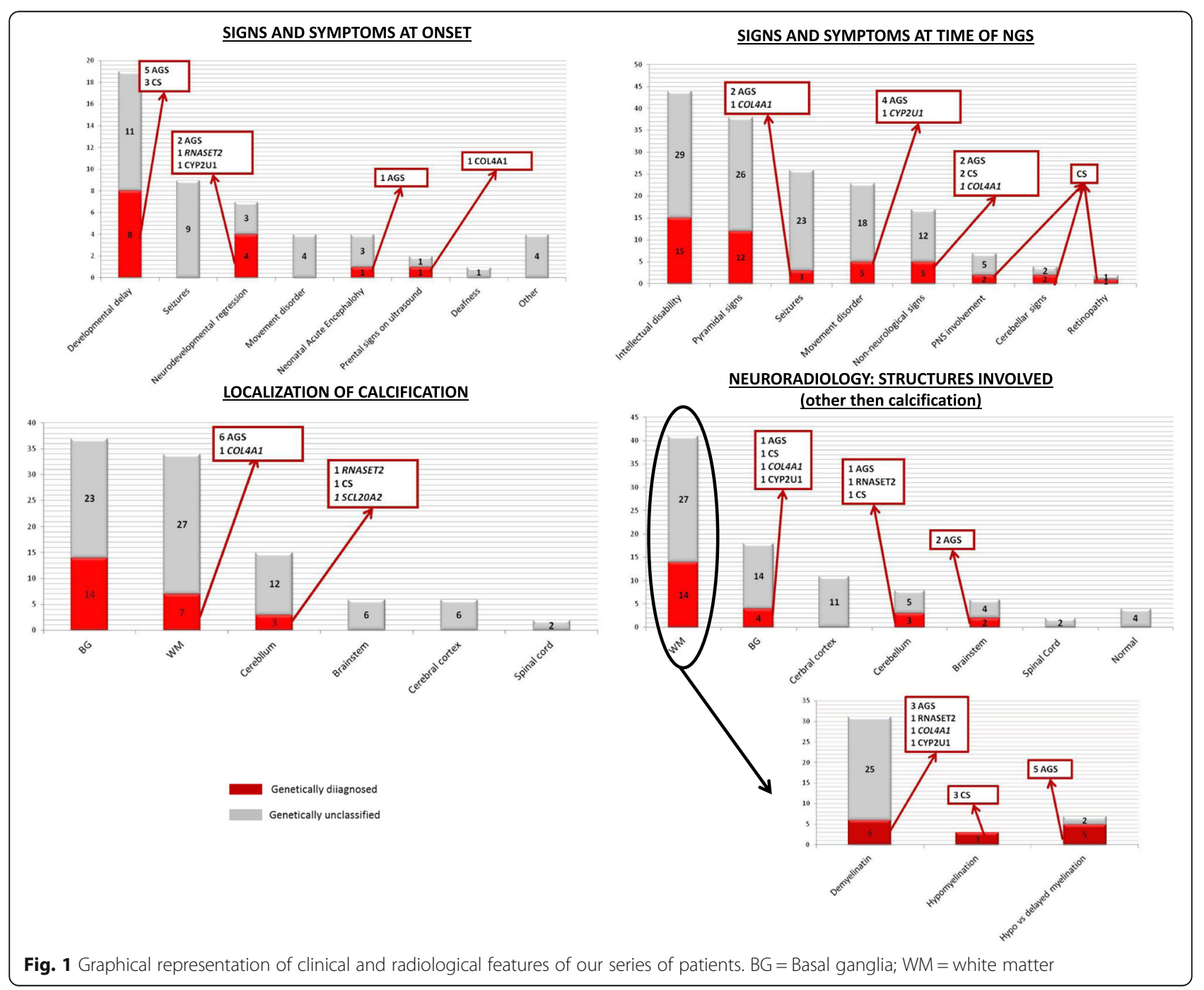


Table 2 Genetic results: Found variants, in silico prediction and frequency in general population Controversial results are highlighted in grey

\begin{tabular}{|c|c|c|c|c|c|c|c|c|c|c|}
\hline $\begin{array}{l}\text { Patient } \\
\text { Number }\end{array}$ & Transcript ID & GENE & CDNA * & PROTEIN & $\begin{array}{l}\text { GENOMIC } \\
\text { POSITION }\end{array}$ & dbSNP ID & ALLELE & POLYPHEN & SIFT & ExAc \\
\hline 1 & ENST00000336617.7 & RNASEH2B & c. $[529 \mathrm{G}>\mathrm{A}] ;[[529 \mathrm{G}>\mathrm{A}]$ & p.Ala17Thr & chr13: 51519581 & rs75184679 & Hom & probably_damaging $(0.917)$ & tolerated(0.23) & $158 / 120984 / 0$ \\
\hline 2 & ENST00000336617.7 & RNASEH2B & c. $[529 \mathrm{G}>\mathrm{A}] ;[529 \mathrm{G}>\mathrm{A}]$ & p.Ala17Thr & chr13: 51519581 & rs 75184679 & Hom & probably_damaging (0.917) & tolerated(0.23) & $158 / 120984 / 0$ \\
\hline 3 & ENST00000336617.7 & RNASEH2B & c. $[529 \mathrm{G}>\mathrm{A}] ;[529 \mathrm{G}>\mathrm{A}]$ & p. Ala177Thr & chr13: 51519581 & rs75184679 & Hom & probably_damaging (0.917) & tolerated(0.23) & $158 / 120984 / 0(0.13 \%)$ \\
\hline 4 & ENST00000336617.7 & RNASEH2B & c. $[529 \mathrm{G}>\mathrm{A}] ;[529 \mathrm{G}>\mathrm{A}]$ & p. Ala17Thr & chr13: 51519581 & rs75184679 & Hom & probably_damaging (0.917) & tolerated(0.23) & $158 / 120984 / 0(0.13 \%)$ \\
\hline 5 & ENST00000336617.7 & RNASEH2B & c. $[529 \mathrm{G}>\mathrm{A}] ;[[529 \mathrm{G}>\mathrm{A}]$ & p. Ala17Thr & chr13: 51519581 & rs 75184679 & Hom & probably_damaging (0.917) & tolerated(0.23) & $158 / 120984 / 0(0.13 \%)$ \\
\hline 6 & ENST00000336617.7 & RNASEH2B & c. $[529 \mathrm{G}>\mathrm{A}] ;[529 \mathrm{G}>\mathrm{A}]$ & p. Ala17Thr & chr13: 51519581 & rs75184679 & Hom & probably_damaging (0.917) & tolerated $(0.23)$ & $158 / 120984 / 0(0.13 \%)$ \\
\hline 7 & ENST00000336617.7 & RNASEH2B & c. $488 C>T$ (;) $529 G>A$ & p.Thr163lle + p.Ala17Thr & $\begin{array}{l}\text { chr13:51517508; } \\
\text { chr13: 51519581 }\end{array}$ & Absent & Comp Het & $\begin{array}{l}\text { probably_damaging( } 1) ; \\
\text { probably_damaging }(0.917)\end{array}$ & $\begin{array}{l}\text { deleterious }(0,5) ; \\
\text { tolerated(0.23) }\end{array}$ & Absent; $158 / 120984 / 0(0.13 \%)$ \\
\hline 8 & ENST00000336617.7 & RNASEH2B & c. [529G>A] ; [ex9-10-11del] & p. Ala177Thr+?? & chr13: 51519581;/ & $\begin{array}{l}\text { rs75184679; } \\
\text { Absent }\end{array}$ & Comp Het & probably_damaging $(0.917)$; / & tolerated(0.23); & 158/120984/0 (0.13\%); Absent \\
\hline 9 & ENST00000508775.5 & RNASET2 & c. [145G>T]; [397_399delAAG] & p.Glu49* + p.Lys133del & $\begin{array}{l}\text { chr6: } 167365978 ; \\
\text { chr6: } 167352429\end{array}$ & $\begin{array}{c}\text { Absent; } \\
\text { rs35266845 }\end{array}$ & Comp Het & & & Absent; $2 / 120036(0.0016 \%)$ \\
\hline 10 & ENST00000265038.9 & ERCC8 & c. $[797 \mathrm{~A}>C] ;[797 \mathrm{~A}>C]$ & p. Asp266Ala & chr5:60194149 & Absent & Hom & probably_damaging(1) & deleterious $(0)$ & Absent \\
\hline 11 & ENST00000355832.9 & ERCC6 & c. $[229 C>T] ;[2143 G>T]$ & p.Arg77* + p.Gly715* & $\begin{array}{l}\text { chr10:50740782; } \\
\text { chr10:50690759 }\end{array}$ & Absent & Comp Het & & & Absent; 3/121218 (0.00245\%) \\
\hline 12 & ENST00000355832.9 & ERCC6 & c.1071delA (;) 2203C>T & $\begin{array}{l}\text { p.Asp358Thrfs*2+ } \\
\text { p.Arg735* }\end{array}$ & $\begin{array}{l}\text { chr10: 50732404; } \\
\text { chr10: 50686483 }\end{array}$ & $\begin{array}{c}\text { Absent; } \\
\text { rs121917901 }\end{array}$ & Comp Het & & & Absent; 11/121402 (0.009\%) \\
\hline 13 & ENST00000375820.8 & COL4A1 & c. $[3041 \mathrm{G}>\mathrm{A}]$ & p. Gly1014Asp & chr13: 110828788 & Absent & Het & probably_damaging(1) & deleterious $(0)$ & Absent \\
\hline 15 & ENSTO0000332884.10 & CYP2U1 & $\begin{array}{l}\text { c. [1288+1G>A]; } \\
\text { [1545_1546delTTAC] }\end{array}$ & p.Pro516Argfs*8 & $\begin{array}{l}\text { chr4: 108868694; } \\
\text { chr4:108871486 }\end{array}$ & Absent & Comp Het & & & 1/120026 (0.00083\%); Absent \\
\hline 16 & ENST00000367590.8 & XPR1 & c. $[1963 C>T]$ & p.Arg655Cys & chr1: 180849366 & Absent & Het & probably_damaging (0.974) & deleterious (0) & $3 / 121408(0.0025 \%)$ \\
\hline 17 & ENSTO0000294618.11 & DOCK6 & c. $[1169 \mathrm{~A}>\mathrm{G}] ;[5939+2 \mathrm{~T}>\mathrm{C}]$ & $\begin{array}{l}\text { p. Tyr390Cys + altered } \\
\text { splicing }\end{array}$ & $\begin{array}{l}\text { chr19:11354322; } \\
\text { chr19:11311390 }\end{array}$ & $\begin{array}{l}\text { Absent; } \\
\text { rs201387914 }\end{array}$ & Comp He & probably_damaging(1);/ & deleterious $(0)$ & $\begin{array}{l}\text { 1/109332/0 (0.000915\%); } \\
38 / 91452 / 0(0.041 \%)\end{array}$ \\
\hline
\end{tabular}

Hom Homozygous, Het heterozygous, Comp Compound

thirty-eight (76\%), seizures in twenty-six (52\%), movement disorder in twenty-three (46\%), non-neurological signs and symptoms in seventeen (34\%), peripheral nerve involvement in seven $(14 \%)$, cerebellar signs in four $(8 \%)$ and retinopathy in two (4\%).

\section{Neuroradiology}

First MRI was performed at a mean age of 6 years (range: neonatal to 30 years; $25^{\circ}$ percentile 7 months, $75^{\circ}$ percentile 7 years). Follow-up MRI was available in thirty out of fifty patients, the meantime from the first MRI was 4 years (range 2 months to 17 years, $25^{\circ}$ percentile 14 months $50^{\circ}$ percentile 5 years). Beside the presence of calcification, additional MRI abnormalities were observed in forty-six out of fifty subjects. Forty-one showed white matter involvement, of which thirty-one (76\%) presented a pattern suggestive of demyelination, three (7\%) of hypomyelination, whereas in seven (17\%) it was not possible to distinguish between hypomyelination and delayed myelination because of the too young age and absence of follow-up MRI. Basal ganglia alterations other than calcification were present in eighteen out of fifty patients (36\%). These abnormalities consisted in volume loss without signal abnormalities and in the constext of a global cerebral atrophy in ten of them (55\%), abnormal signal with or without atrophy in five (27\%) and sign of cavitation consistent with bilalteral striatal necrosis in three (16\%). Cerebral cortex was involved in eleven
(22\%), of which four (36\%) presented cortical atrophy, four (36\%) cortical malformation (polymicrogiria in all cases) and three (28\%) signs of ischemic damage (watershed stroke in all the three); it is of note that in the last three patients the acquired lesions where found in the context of a more complex and likely genetic encephalopathy and therefore included in the study. Cerebellum was altered in eight out of fifty patients (16\%) and brainstem in six (12\%). Spinal cord MRI was performed in twenty out of fifty patients and signal abnormalities were disclosed in two.

First CT scan was performed at a mean age of 6 years (range: neonatal to 30 years; $25^{\circ}$ percentile 8 months, $75^{\circ}$ percentile 8 years). Follow-up CT was available in eighteen out of fifty patients, the mean time from the first CT was 4 years (range: 7 months to 13 years; $25^{\circ}$ percentile 20 months $50^{\circ}$ percentile 6 years). Cerebral calcification were evident in basal ganglia in thirty-seven (74\%) patients, in white matter in thirty-four $(68 \%)$, in the cerebellum in fifteen $(30 \%)$, in the brainstem in six $(12 \%)$, in cerebral cortex in six $(12 \%)$, in spinal cord in two $(4 \%)$.

\section{Clinical and genetic diagnosis}

Based on clinical, radiological and laboratory findings an etiological hypothesis was suspected in thirty patients while the other twenty were classified as affected by an undetermined condition. NGS analysis provided positive 
results in sixteen out of fifty patients (32\%) leading to a definite etiological diagnosis in fourteen out of sixteen. Variants of uncertain significance were found in two subjects.

Thirteen out of thirty with suspected diagnosis and only one out of twenty classified as undetermined condition finally received a genetic diagnosis. The genetic diagnosis was consistent with the clinical hypothesis in all but one who had been clinically diagnosed as AGS and then found to carry biallelic mutations in RNASET2 (more details are given below).

The most frequent diagnosis in our series was AGS which is the most frequent leukodystrophy with cerebral calcification. Diagnosis of AGS repose on a number of clinical, radiological and biological criteria [15] (Table 3). Sixteen patients were suspected to suffer from AGS, nine received genetic confirmation. Twelve out of the sixteen suspected AGS fulfilled classic diagnostic criteria, in eight of them mutations in the seven known AGS-genes were found, while one was the RNASET2 mutated patient and three were finally diagnosed as AGS mutation negative. Four patients fulfilled only partially diagnostic criteria of AGS, one of them carried biallelic RNASEH $2 B$ mutations and received a diagnosis of atypical AGS, the other three remained unclassified.

In two patients PFBC was suspected both remained unclassified.

Two patients presented a clinical and radiological picture suggesting a Collagen IV- related disorder (Fig. 2), one has been confirmed while in the other no pathogenic mutations have been found. Three patients was suspected to suffer from Cockayne Syndrome (Fig. 3), NGS confirmed the clinical hypothesis in all.

One patient was suspected to suffer from Leukodystrophy with Cysts and Calcification (LCC), two from
ADAR1-related striatal degeneration, one from Occludin-related condition, one from Adams Oliver Syndrome, one from Revesz Syndrome. In none of these 6 patients pathogenic mutations have been found. It is of note that when our gene panel has been designed the molecular cause of LCC was still obscure. Morover DOCK6 was the only AOS-gene included in the panel because of limited space availability and because it was the one most commonly associated with cerebral calcification.

Among the twenty-eight patients in which no etiological hypothesis was formulated, pathogenic mutations were found in only one. She was the young woman suffering from CYP2U1-related condition.

\section{Atypical AGS (patient 6, Fig. 4)}

This 13 year-old boy presented at 9 months of age with subacute onset of neurodevelopmental regression signs of pyramidal and extrapyramidal involvement, and evolved to a spastic-dystonic tetraplegia with global hypokinesia but with a good social interaction. He never developed microcephaly or extraneurological signs. Serial MRIs showed the presence of non -progressive multifocal white matter abnormalities and multiple CT scans revealed non progressive bilateral spots of calcification in basal ganglia. Cerebrospinal fluid (CSF) cell count tested at 14 months, CSF Interferon alpha tested at 3 years, Interferon stimulated Genes analysis (interferon signature) tested at 12 years, were all normal. Despite not all criteria for the diagnosis of AGS were fulfilled NGS disclosed a common missense mutation of RNA$S E H 2 B$ in a homozygous state. Given the presence of some un common findings (uncommon MRI pattern [16] and normal CSF cells counts close to clinical onset) a diagnosis of atypical AGS was done.

Table 3 AGS diagnostic criteria

\begin{tabular}{|c|c|}
\hline 1 & $\begin{array}{l}\text { Early onset encephalopathy with psychomotor delay, spasticity, extrapyramidal signs and microcephaly, the latter appearing } \\
\text { in the course of the first year of life. }\end{array}$ \\
\hline 2 & $\begin{array}{l}\text { Calcifications particularly visible at basal ganglia level (putamen, pallidus and thalamus), but also extending to the } \\
\text { periventricular white matter. }\end{array}$ \\
\hline 3 & Cerebral white matter abnormalities. \\
\hline 4 & Cerebral atrophy. \\
\hline 5 & $\begin{array}{l}\text { Exclusion of pre-/perinatal infections, in particular the TORCH complex (toxoplasmosis, rubella, cytomegalovirus, } \\
\text { herpes simplex virus). }\end{array}$ \\
\hline 6 & Chronic lymphocytosis (> 5 cells/mm3) on CSF examination, not accompanied by any other sign of an infectious process. \\
\hline 7 & Raised INF-alpha in the CSF (> $2 \mathrm{IU} / \mathrm{ml})$. \\
\hline 8 & Elevated neopterins and biopterins in CSF, sometimes associated with decreased folates. \\
\hline 9 & $\begin{array}{l}\text { Important systemic symptoms in the early stages of the disease include irritability, feeding and sleeping difficulties, } \\
\text { unexplained fevers and the appearance of chilblain-like skin lesions on the fingers, toes and ears. }\end{array}$ \\
\hline 10 & $\begin{array}{l}\text { Genetic screening for mutations in the seven genes known to cause AGS allows definitive confirmation of the diagnosis } \\
\text { in the majority ( } 95 \%) \text { of cases. }\end{array}$ \\
\hline
\end{tabular}



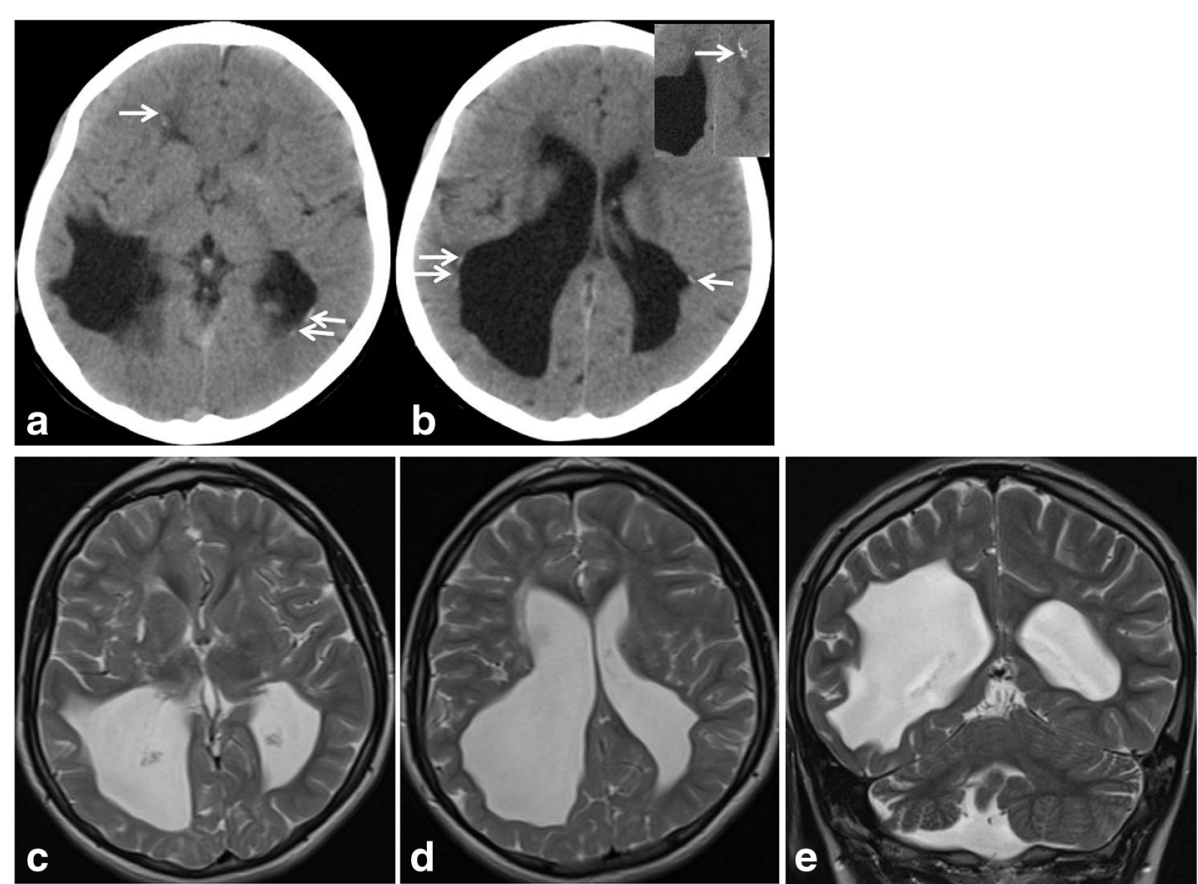

Fig. 2 COL4A1-related leukoencephalopathy -Brain CT, a and $\mathbf{b}$ and brain MRI, c-e, show «ex vacuo» enlarged lateral ventricles with irregular profiles mainly posteriorly and on the right associated with lacunar infarctions in the right basal ganglia. CT demonstrate small sub-ependymal calcification and insert in $\mathbf{b}$ show calcification in the sub-cortical white matter (arrows). Coronal image in E demonstrate right posterior cranial fossa and right cerebellar hemisphere hypoplasia
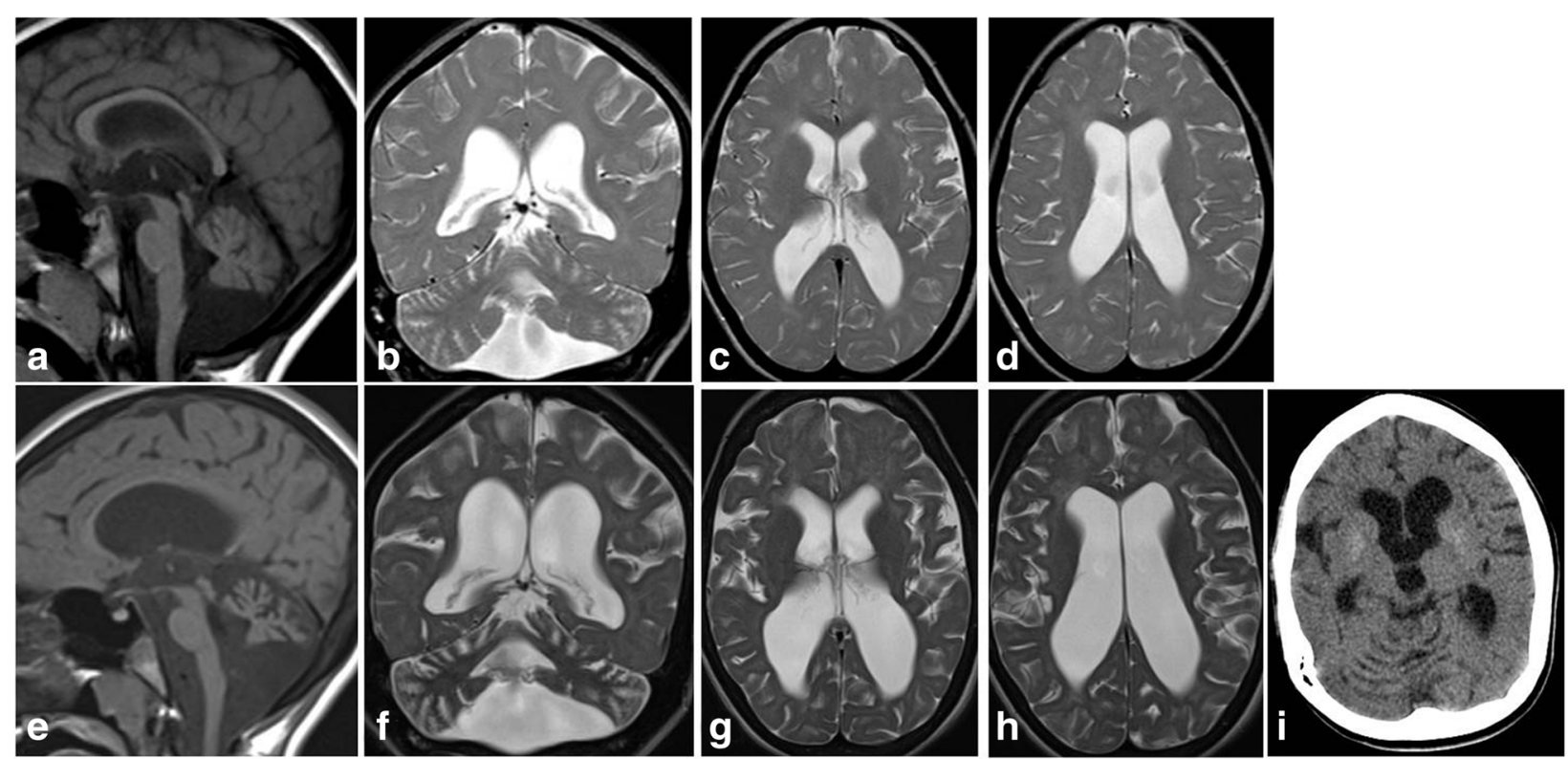

Fig. 3 Cockayne syndrome -Brain MRI at age 5 years, top (a-d), brain MRI at age 9 years, bottom (e-h), and brain CT at age 9, (i). Note the diffuse cerebral atrophy progression, mainly in the posterior fossa, and the diffuse slight white matter hyperintensity due to hypomyelinating leukoencephalopathy. $\subset$ demonstrate faint hyperdensity in the putamina due to fine calcification 


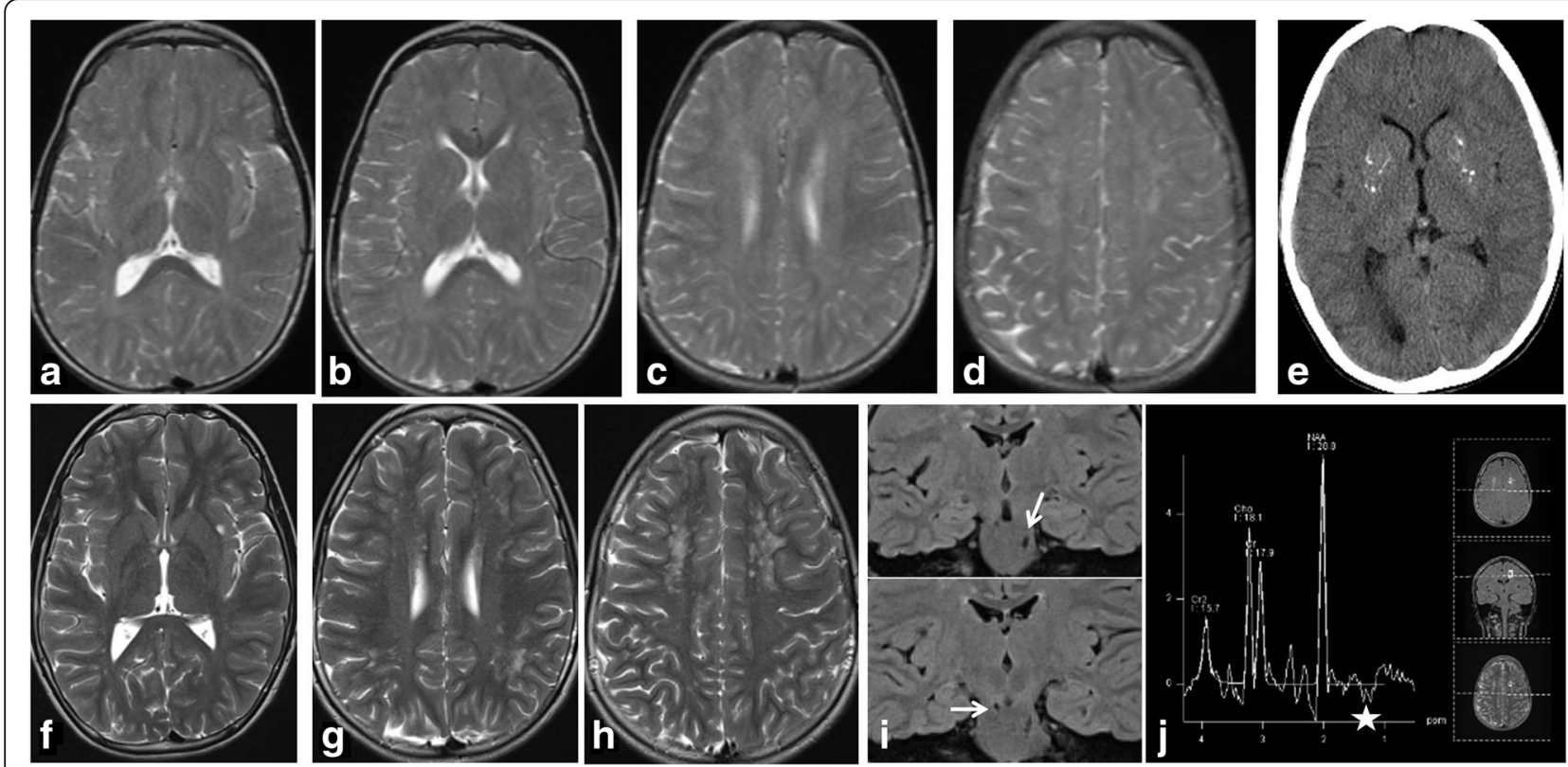

Fig. 4 Atypical AGS - Top, brain MRI at 4 years old, (a-d), demonstrate mildly hyperintense T2 signal of the white matter relative to the cortex probably due to delayed myelination; CT show (e) basal ganglia calcification. Bottom, (f-j), brain MRI at 11 years old demonstrate myelination progression and multiple small confluent T2 hyperintensities in the sub-cortical areas mainly in F1. Enlarged perivascular spaces are visible in the brainstem (arrows in $\mathbf{i}$ ); MRS in $\mathbf{j}$ shows lactate (asterisk) in the abnormal frontal white matter

\section{RNASET2-related leukodystrophy}

Patient 9 was diagnosed as affected by RNASET2-related leukodystrophy. The clinical and radiological picture was quite different compared to the one described in this condition and overlapped significantly with AGS as we described elsewhere [17].

\section{CYP2U1-related encephalopathy (Fig. 5)}

In patient 15 biallelic mutations of CYP2U1 were found. This case has previously been reported by Iodice et al. [18] and was characterized by onset at the end of the first year of life of a slowly progressive encephalopathy with spastic tetraplegia, mild upper limb dystonia and borderline cognitive performance. An interesting non-reported finding was the presence on MRI not only of spotty multifocal white matter abnormalities and pallidal calcification but also of bilateral putaminal T2 hyperintensisty, (Fig. 5) which has never been reported in CYP2U1-related condition so far. Given the complex clinical and radiological picture of this and other reported patients [19] we propose to consider CYP2U1 mutations as the cause of a broader phenotypic spectrum ranging from pure spastic paraparesis (SPG56) to a veritable encephalopathy with cerebral calcification.

\section{Uncertain genetic results}

In 2 patients NGS analysis demonstrated ambiguous results.

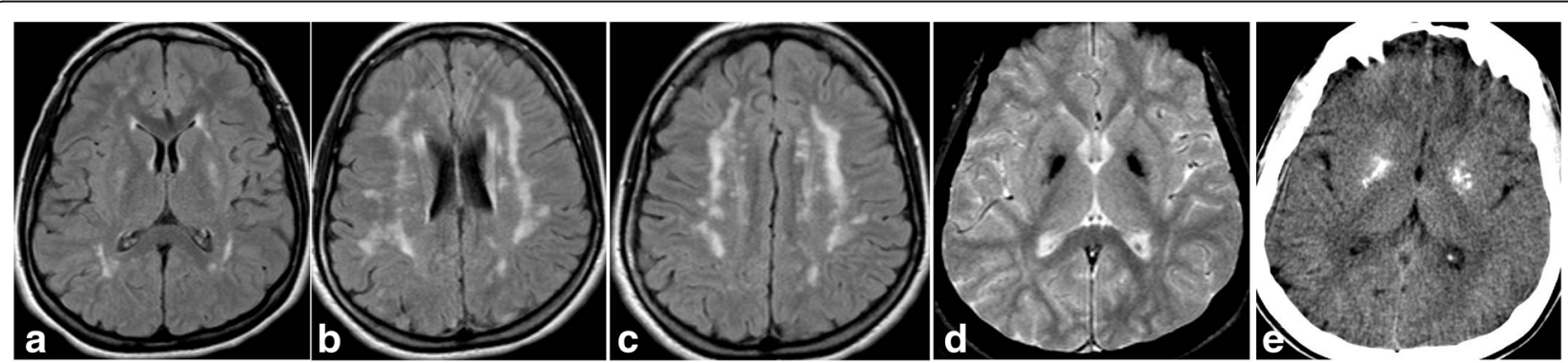

Fig. 5 CYP2U1-related disorder- Brain MRI at 25 years old, FLAIR images in (a-c) and FFE image in (d), show bilateral hyperintensities in the putamina and confluent marked hyperintensities in the sub-cortical regions of cerebral hemispheres. In $\mathbf{d}$ and in e (CT), bilateral pallidal marked hypointensity and hyperdensity due to calcification is seen. Examination performed 7 years later was unchanged (data not shown) 
In patient 17 biallelic mutations were found in DOCK6, one of the genes of Adams Oliver Syndrome (AOS) [1]. Our patient did not show the clinical presentation of AOS, but conversely she fulfilled clinical criteria for Aicardi-Goutières Syndrome.

The second patient (patient 16) was found to carry a mutation in a PFBC-related gene: XPR1. This is a 9 year-old boy that presented at 3 years of age with acute onset of generalized dystonia shortly after an intercurrent viral infection. MRI showed bilateral striatal lesions hyperintense on T2wi associated with bilateral striatal calcification. At present we can just report these observations, more data are needed and functional studies are ongoing in order to explore the actual role of the mutations.

\section{Genetically unclassified patients}

In thirtyfour patients genetic analysis resulted negative. These included seven patients who fulfilled criteria for a specific clinical diagnosis [three AGS, one AOS, one PFBC (Fig. 6), one Revesz Syndrome, one LCC] confirming the genetic heterogeneity underlying some peculiar clinical syndromes and the partial knowledge of their genetic bases, even in the "genome" era.

In the group of negative patients is included patient 14, a girl now aged 16 affected by a classical Down Syndrome. From the age of 14 years she started to present akynetic-rigid parkinsonism with tremor in the upper limbs. She underwent an MRI showing bilateral rock-shaped calcification in the pallidal nuclei, putamina and dentate nuclei. Pallidal calcification in Down Syndrome has been reported previously and interpreted as a sign of premature aging [20]. The clinical and radiological picture in our case was quite peculiar and prompted us to widen the molecular differential diagnosis leading to the identification the unreported variant in one of the PFBC-related gene, namely SLC20A2 c.[1301C > G]. The variant was predicted to be "disease causing" in silico (Polyphen-2, SIFT, MutationTaster). Segregation analysis revealed that the healthy father carried the same variant. He underwent a cerebral CT scan that resulted normal. It is difficult to ascertain if cerebral calcification were only related to 21 trisomy or if the concomitant presence of the $S L C 20 A 1$ variant played also a role.

In the group of unclassified patients we were able to identify some subset of patients sharing similar peculiar phenotypes. This was the case of a previously reported patient affected by a leukoencephalopathy with spinal cord calcification of unknown genetic etiology [21]. A second patient with a strikingly similar phenotype was present in our series and we recently identified a third patient outside the study sample. Based on the similar phenotype, we started looking for a possible common genetic abnormality and this approach led to the identification of the genetic cause of the disease [22].

\section{Discussion and conclusions}

We here describe the clinical and radiological features of a series of fifty patients affected by a pediatric onset encephalopathy with cerebral calcification. Age at onset was quite variable but the majority of patients presented during the first 2 years life. Intellectual disability and pyramidal signs were commonly observed, while movement disorders and epilepsy were less frequent. Cerebellar signs, peripheral nerve and retinal involvement were rare. They were present in 3 subjects and they have been essential hints to reach the etiological diagnosis of CS.

In our series, white matter involvement was present in the majority of patients. A demyelinating pattern was the most frequently observed. Hypomyelination was present only in patients affected by CS while among subjects with "uncertain" pattern, AGS was the only diagnosis, confirming that inadequate myelination can be observed in AGS patients [16]. Only one subject presented a clinical picture consistent with isolated dystonia but associated to bilateral pallidal calcification. Dedicated gene panels for primary and secondary movement disorders did not allow a definite diagnosis in this subject.

The most frequent localization of cerebral calcification was basal ganglia. However, movement disorders were observed only in a minority of patients suggesting that, at least in some cases, calcifications could be just an

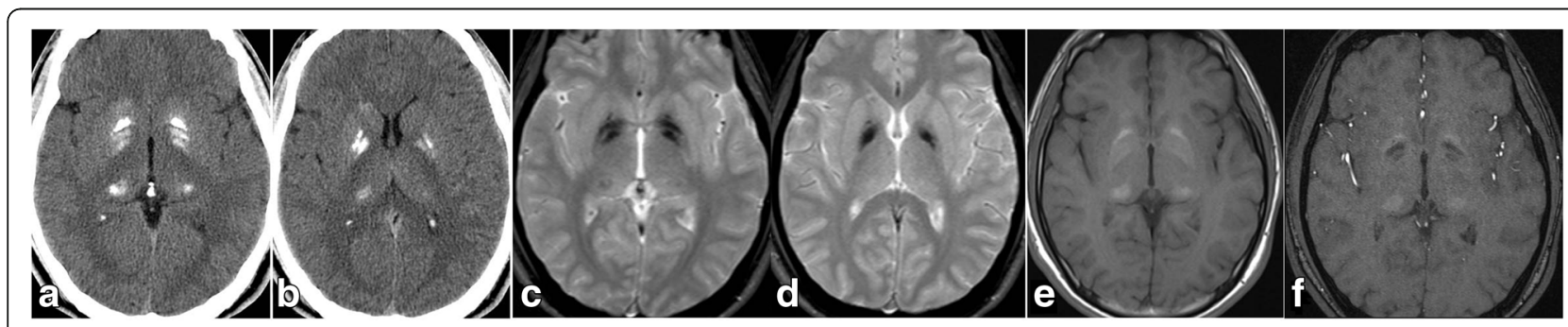

Fig. 6 PFBC - Brain CT (a, b) and MRI (c-f) at 17 years old show bilateral coarse calcification in globus pallidus and thalamus. Note the different signal of calcification on T2 FFE, $\mathbf{c}$ and $\mathbf{d}$, T1-weighetd, $\mathbf{e}$, and time-of-flight (TOF, $\mathbf{f}$ ) images 
epiphenomenon of the disease without a significant role in the genesis of clinical signs and symptoms.

AGS was the most frequent diagnosis and RNASEH $2 B$ was the most commonly involved gene. This result is in line with literature where AGS is described as the most common pediatric onset encephalopathy with cerebral calcification [23] and RNASH $2 B$ as the gene most commonly involved [2].

In our study genetic analysis and deep phenotyping were strictly connected. The presence of cerebral calcification represented the criterion for selecting the initial group of patients. Subsequently a very careful clinical work of investigating relevant clinical and radiological signs was the crucial point that resulted extremely important in analyzing NGS data. It was indeed the central point in order to address the attention to specific genes and to evaluate the significance of the various variants found by the customized panel. This approach led us to solve a considerable number of cases (32\%). Moreover we made a rapid diagnosis in patients affected by classic phenotypes of diseases that can be caused by different genes, such as AGS, or by large genes such as COL4A1 and COL4A2. In fact in both these situations traditional Sanger sequencing appears to be obsolete, time consuming and not cost-effective. Our results suggest that all patients presenting cerebral calcification should undergo first of all to an attentive and deep phenotyping process done by a qualified team of experienced professionals. If this leads to a clinical hypothesis the next step is to perform customized gene panel except in the case of AGS where the common mutation p.Ala177Thr in RNASEH2B/AGS2 should be tested before, at least in patients with Italian background. Whole exome sequencing should be chosen as first line genetic analysis in the other patients.

As we said cerebral calcification represent a useful diagnostic hint, but they should be carefully evaluated when found in advanced disease stages because in these cases it could become a confounding factor. Calcium deposition indeed can be secondary to white matter degeneration and can be observed in advanced stages of some leukodystrophies not usually characterized by cerebral calcification such as X-linked adrenoleukodystrophy [24-26] or Alexander disease [27-30]. This was the case of one patient of our series who was referred for diagnostic work-up of a severe leukodystrophy with cerebral calcification. When CT was performed and calcification was found she presented an advanced stage of her progressive condition. Gene panel for cerebral calcification resulted negative and the girl was lately diagnosed as affected by D-bifunctional protein deficiency (DBPD). As far as we know cerebral calcification has not been reported so far in patients affected by DBPD and it probably represent an epiphenomenon of severe white matter degeneration instead of an unreported feature of the disease.

Cerebral calcification was studied by $\mathrm{CT}$ in all patients included in our series. In clinical practice CT has almost uniformly been substituted by MRI and literature report controversial data about the best technique to be used to evaluate the presence of cerebral calcification [31-33]. From one side it seems that $\mathrm{CT}$ is more powerful for the identification of small calcification [33] such as those observed in COL4A1-related disorder, but at the same time it has to take into account the risk related to exposure to ionizing radiation [34]. More studies will be necessary to solve this problem. From our perspective, and as it appears clear from our series, in all patients presenting a genetic encephalopathy of unknown aetiology cerebral calcification should be looked for. At current state of things we deem that an attentive evaluation by MRI specific sequences should be initially chosen. If MRI is uninformative low-dose CT should be performed as second option.

With our study we identified new phenotypes associated with already known genes (i.e. RNASET2), but also patients presenting classical phenotypes who tested negative for all known genes and therefore good candidates for exome or whole genome sequencing.

Lastly, management of patients in a restricted number of referral centers and the strict multidisciplinary collaboration among these centers allowed identifying unrelated patients with similar clinical and radiological phenotypes. This led to identify new syndromic entities and their molecular bases. Our approach confirms that only a very close collaboration between clinicians, neuroradiologists and geneticists can provide better results from the new generation molecular techniques.

\section{Abbreviations}

AGS: Aicardi-Goutières syndrome; AOS: Adams Oliver Syndrome; CDS: Coding sequence; CS: Cockayne syndrome; CSF: Cerebrospinal Fluid; CT: Computed Tomography; KD: Krabbe disease; NGS: Next Generation Sequencing; PFBC: Primary Familial Brain Calcification

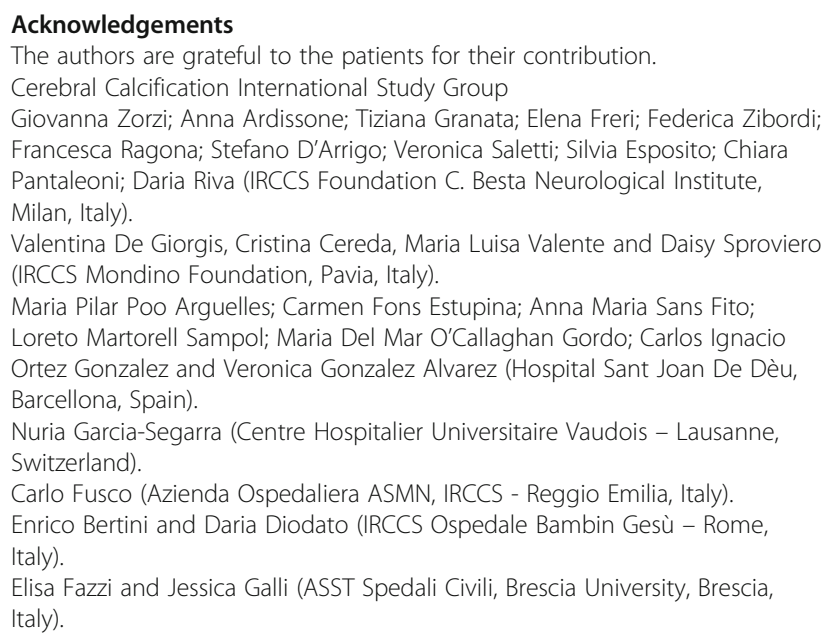




\section{Funding}

This study was supported by grants of the Italian Ministry of Health RC 2017-2018 to IRCCS Mondino Foundation, Pavia, Italy. No additional or external funding was received for this project.

\section{Availability of data and materials}

The datasets used and analyzed during the current study are available from the corresponding author.

\section{Authors' contributions}

DT, SO conceived and designed the study, collected data, drafted the manuscript; CP, CR carried out the molecular genetic studies; AP, LP performed neuroimmaging evaluation; AD, MC, IM, NN, JC, AGC, BPD recruited patients and collected clinical data. BG: conceived and designed the study, supervised molecular genetic studies; Authors included in the "Cerebral Calcification International Study Group" collected patients. All authors read and approved the final manuscript.

\section{Ethics approval and consent to participate}

This study adheres to the principles of the Helsinki Declaration and was carried out through routine diagnostic activity; formal ethics review was therefore not requested by our institutional ethical committee for the targeted next generation sequencing.

\section{Consent for publication}

All families provided written informed consent for genetic testing and publication of clinical and genetic data according to the italian bioethics laws.

\section{Competing interests}

The authors declare that they have no competing interests.

\section{Publisher's Note}

Springer Nature remains neutral with regard to jurisdictional claims in published maps and institutional affiliations.

\section{Author details \\ ${ }^{1}$ Child Neurology Unit, IRCCS Foundation C. Besta Neurological Institute, Milan, Italy. ${ }^{2}$ Child Neurology Unit, V. Buzzi Children's Hospital, Milan, Italy. ${ }^{3}$ Molecular Neurogenetics Unit, Movement Disorders Diagnostic Section, IRCCS Foundation C. Besta Neurological Institute, Milan, Italy. ${ }^{4}$ Department of Neuroradiology, IRCCS Mondino Foundation, Pavia, Italy. ${ }^{5}$ Child Neurology and Psychiatry Unit, IRCCS Mondino Foundation, Pavia, Italy. ${ }^{6}$ Neuropsychiatry and Neurorehabilitation Unit, IRCCS Medea, Bosisio Parini Lecco, Italy. ${ }^{7}$ Department of Medicine and Surgery, PhD Programme in Molecular and Translational Medicine, University of Milan Bicocca, Monza, Italy. ${ }^{8}$ Department of Child Neurology, Pediatric Research Institute, Hospital Sant Joan de Déu, University of Barcelona, Barcelona, Spain. ${ }^{9}$ Department of Neuroradiology, IRCCS Foundation C. Besta Neurological Institute, Milan, Italy.}

Received: 26 February 2018 Accepted: 21 June 2018

Published online: 16 August 2018

\section{References}

1. Hassed S, Li S, Mulvihill J, Aston C, Palmer S. Adams-Oliver syndrome review of the literature: refining the diagnostic phenotype. Am J Med Genet A. 2017;173:790-800

2. Crow YJ, Chase DS, Lowenstein Schmidt J, Szynkiewicz M, Forte GM, Gornall HL, Oojageer A, Anderson B, Pizzino A, Helman G, et al. Characterization of human disease phenotypes associated with mutations in TREX1, RNASEH2A, RNASEH2B, RNASEH2C, SAMHD1, ADAR, and IFIH1. Am J Med Genet A. 2015;167A:296-312.

3. Livingston JH, Graziano C, Pysden K, Crow YJ, Mordekar SR, Moroni I, Uziel G. Intracranial calcification in early infantile Krabbe disease: nothing new under the sun. Dev Med Child Neurol. 2012;54:376-9.

4. Lehman AM, Schultz KR, Poskitt K, Bjornson B, Keyes R, Waters PJ, Clarke LA, Everett R, McConnell D, Stockler S. Intracranial calcification after cord blood neonatal transplantation for krabbe disease. Neuropediatrics. 2009;40:189-91.

5. Shanley DJ. Mineralizing microangiopathy: CT and MRI. Neuroradiology. 1995:37:331-3.
6. Metoki T, Mugikura S, Higano S, Ezura M, Matsumoto Y, Hirayama K, Takahashi S. Subcortical calcification on CT in dural arteriovenous fistula with cortical venous reflux. AJNR Am J Neuroradiol. 2006;27:1076-8.

7. Goswami R, Sharma R, Sreenivas V, Gupta N, Ganapathy A, Das S. Prevalence and progression of basal ganglia calcification and its pathogenic mechanism in patients with idiopathic hypoparathyroidism. Clin Endocrinol. 2012;77:200-6.

8. Mochida GH, Ganesh VS, Felie JM, Gleason D, Hill RS, Clapham KR, Rakiec D, Tan WH, Akawi N, Al-Saffar M, et al. A homozygous mutation in the tightjunction protein JAM3 causes hemorrhagic destruction of the brain, subependymal calcification, and congenital cataracts. Am J Hum Genet. 2010;87:882-9.

9. O'Driscoll MC, Daly SB, Urquhart JE, Black GC, Pilz DT, Brockmann K, McEntagart M, Abdel-Salam G, Zaki M, Wolf NI, et al. Recessive mutations in the gene encoding the tight junction protein occludin cause band-like calcification with simplified gyration and polymicrogyria. Am J Hum Genet. 2010;87:354-64.

10. Volonghi I, Pezzini A, Del Zotto E, Giossi A, Costa P, Ferrari D, Padovani A. Role of COL4A1 in basement-membrane integrity and cerebral small-vessel disease. The COL4A1 stroke syndrome. Curr Med Chem. 2010;17:1317-24.

11. Livingston $J H$, Stivaros S, MS VDK, Crow YJ. Recognizable phenotypes associated with intracranial calcification. Dev Med Child Neurol. 2012;55:46-57.

12. Jeanne M, Labelle-Dumais C, Jorgensen J, Kauffman WB, Mancini GM, Favor J, Valant V, Greenberg SM, Rosand J, Gould DB. COL4A2 mutations impair COL4A1 and COL4A2 secretion and cause hemorrhagic stroke. Am J Hum Genet. 2012;90:91-101.

13. Wang C, Li Y, Shi L, Ren J, Patti M, Wang T, de Oliveira JR, Sobrido MJ, Quintans B, Baquero M, et al. Mutations in SLC20A2 link familial idiopathic basal ganglia calcification with phosphate homeostasis. Nat Genet. 2012;44: 254-6.

14. Vanderver A, Prust M, Tonduti D, Mochel F, Hussey HM, Helman G, Garbern $J$, Eichler $F$, Labauge $P$, Aubourg P, et al. Case definition and classification of leukodystrophies and leukoencephalopathies. Mol Genet Metab. 2015;114: 494-500.

15. Orcesi S, La Piana R, Fazzi E. Aicardi-Goutieres syndrome. Br Med Bull. 2009; 89:183-201.

16. La Piana R, Uggetti C, Roncarolo F, Vanderver A, Olivieri I, Tonduti D, Helman G, Balottin U, Fazzi E, Crow YJ, et al. Neuroradiologic patterns and novel imaging findings in Aicardi-Goutieres syndrome. Neurology. 2016;86: 28-35.

17. Tonduti D, Orcesi S, Jenkinson EM, Dorboz I, Renaldo F, Panteghini C, Rice Gl, Henneke M, Livingston JH, Elmaleh M, et al. Clinical, radiological and possible pathological overlap of cystic leukoencephalopathy without megalencephaly and Aicardi-Goutieres syndrome. Eur J Paediat neurol. 2016:20:604-10.

18. Iodice A, Panteghini C, Spagnoli C, Salerno GG, Frattini D, Russo C, Garavaglia B, Fusco C: Long-term follow-up in spastic paraplegia due to SPG56/CYP2U1: age-dependency rather than genetic variability? J Neurol 2017;264:586-8

19. Kariminejad A, Schöls L, Schüle R, Tonekaboni SH, Abolhassani A, Fadaee M, Rosti RO, Gleeson JG. CYP2U1 mutations in two Iranian patients with activity induced dystonia, motor regression and spastic paraplegia. Eur J Paediatr Neurol. 2016;20:782-7.

20. Arai Y, Yoshihara S, linuma K. Brain CT studies in 26 cases of aged patients with Down syndrome. No To Hattatsu. 1995;27:17-22.

21. Orcesi S, La Piana R, Uggetti C, Tonduti D, Pichiecchio A, Pasin M, Viselner G, Comi GP, Del Bo R, Ronchi D, et al. Spinal cord calcification in an earlyonset progressive leukoencephalopathy. J Child Neurol. 2011;26:876-80.

22. Ardissone A, Tonduti D, Legati A, Lamantea E, Barone R, Dorboz I, Boespflug-Tanguy O, Nebbia G, Maggioni M, Garavaglia B, et al. KARSrelated diseases: progressive leukoencephalopathy with brainstem and spinal cord calcifications as new phenotype and a review of literature. Orphanet J Rare Dis. 2018;13:45.

23. Livingston JH, Stivaros S, MS VDK, Crow YJ. Recognizable phenotypes associated with intracranial calcification. Dev Med Child Neurol. 2012;55: 46-57.

24. Inoue Y, Fukuda T, Takashima S, Ochi H, Onoyama Y, Kusuda S, Matsuoka O, Murata R. Adrenoleukodystrophy: new CT findings. AJNR Am J Neuroradiol. 1983:4:951-4

25. Hong-Magno ET, Muraki AS, Huttenlocher PR. Atypical CT scans in adrenoleukodystrophy. J Comput Assist Tomogr. 1987;11:333-6. 
26. Kumar AJ, Rosenbaum AE, Naidu S, Wener L, Citrin CM, Lindenberg R, Kim WS, Zinreich SJ, Molliver ME, Mayberg HS, et al. Adrenoleukodystrophy: correlating MR imaging with CT. Radiology. 1987;165:497-504.

27. Walls TJ, Jones RA, Cartlidge N, Saunders M. Alexander's disease with Rosenthal fibre formation in an adult. J Neurol Neurosurg Psychiatry. 1984; 47:399-403.

28. Howard RS, Greenwood R, Gawler J, Scaravilli F, Marsden CD, Harding AE. A familial disorder associated with palatal myoclonus, other brainstem signs, tetraparesis, ataxia and Rosenthal fibre formation. J Neurol Neurosurg Psychiatry. 1993;56:977-81.

29. Jefferson RJ, Absoud M, Jain R, Livingston JH, MS VDK, Jayawant S. Alexander disease with periventricular calcification: a novel mutation of the GFAP gene. Dev Med Child Neurol. 2010;52:1160-3.

30. Suzuki H, Yoshida T, Kitada M, Ichihashi J, Sasayama H, Nishikawa Y, Mistui Y, Nakagawa M, Kusunoki S. Late-onset Alexander disease with a V87L mutation in glial fibrillary acidic protein (GFAP) and calcifying lesions in the sub-cortex and cortex. J Neurol. 2012;259:457-61.

31. Chen W, Zhu W, Kovanlikaya I, Kovanlikaya A, Liu T, Wang S, Salustri C, Wang Y. Intracranial calcifications and hemorrhages: characterization with quantitative susceptibility mapping. Radiology. 2014;270:496-505.

32. Docampo J, Gonzalez N, Bravo F, Sarroca D, Morales C, Bruno C. Susceptibility-weighted angiography of intracranial blood products and calcifications compared to gradient echo sequence. Neuroradiol J. 2013;26: 493-500.

33. Livingston $\mathrm{JH}$, Stivaros S, Warren D, Crow YJ. Intracranial calcification in childhood: a review of aetiologies and recognizable phenotypes. Dev Med Child Neurol. 2014;56:612-26.

34. Trost MJ, Robison N, Coffey D, Mamey MR, Robison RA. Changing trends in brain imaging technique for pediatric patients with Ventriculoperitoneal shunts. Pediatr Neurosurg. 2018;53:116-20

Ready to submit your research? Choose BMC and benefit from:

- fast, convenient online submission

- thorough peer review by experienced researchers in your field

- rapid publication on acceptance

- support for research data, including large and complex data types

- gold Open Access which fosters wider collaboration and increased citations

- maximum visibility for your research: over $100 \mathrm{M}$ website views per year

At BMC, research is always in progress.

Learn more biomedcentral.com/submissions 